\title{
O ENVOLVIMENTO DA UNIVERSIDADE EM RELAÇÃO AO TEMA VELHICE: a palavra de coordenadores de programas
}

\author{
Meire Cachioni ${ }^{1}$ \\ Luis Enrique Aguilar2
}

\section{Resumo}

Os conhecimentos relacionados às percepções sobre a velhice, gerados nas Instituições de Ensino Superior, são científica e educacionalmente relevantes. Realizamos um estudo com quinze coordenadores de programas na área gerontológica. Os objetivos visaram: a) conhecer trabalhos desenvolvidos na área gerontológica; b) conhecer a percepção dos coordenadores sobre o tema velhice nas instituições. Três instituições foram investigadas, sendo uma privada e duas públicas. O instrumento foi um questionário para levantamento do envolvimento da Universidade em relação ao tema velhice. Análises de conteúdo, mediante as quais foram levantadas categorias e subcategorias de respostas, apontaram que os coordenadores estão envolvidos na área gerontológica através dos programa Universidade Aberta à Terceira Idade, de núcleos de estudo ou pesquisa e dos programas de pós-gradução. Os benefícios atribuídos à presença dos idosos na universidade mais relatados foram respectivamente: contato intergeracional, relatados em todas as universidades; geração de conhecimento gerontológicos; gestão do novo segmento etário/relação da universidade com a população; mudanças de atitudes positivas em relação à velhice.

Palavras-chave: Velhice. Universidade. Programas Área Gerontológica.

\section{Introdução}

A educação é um processo contínuo vivido pelo ser humano ao longo de toda a vida. Não só em contato com a escola - principal agência encarregada de realizá-la, e por intermédio da qual a sociedade transmite, conserva e aperfeiçoa seus valores - como também em contato com as demais

\footnotetext{
1 Psicóloga. Doutora em Educação com concentração em Gerontologia pelo programa de Pós-Graduação em Gerontologia da Unicamp. Pós-Doutora em Educação pela mesma instituição. Docente do Curso de Gerontologia da Escola de Artes, Ciências e Humanidades da Universidade de São Paulo. E-mail: meirec@ymail.com

2 Doutor em Educação pela Unicamp. Pesquisador do Laboratório de Políticas Públicas e Planejamento Educacional, LaPPlanE. Ex-Coordenador do Programa de Pós-Graduação/FE/ Unicamp e atualmente Membro da Comissão de Avaliação da Sub-Área Educação da Capes. E-mail: luis.aguilar@merconet.com.br 
instituições sociais e agências educacionais. À medida que amadurece, o leque de influências biológicas, psicológicas, sociais e culturais torna-se cada vez mais amplo e aumenta a possibilidade de auto-educação do ser humano. Nem a criança nem o adulto, por menos letrado e por menos intelectualmente sofisticado que este seja, são um papel em branco. Ao longo de toda a vida, ninguém é somente ensinado ou alvo da ação condutora da educação proporcionada por outrem.

Lembrar esses princípios é reafirmar a fé na possibilidade de progresso dos indivíduos de todas as idades, dos grupos sociais e da sociedade por intermédio da educação. Associá-los a iniciativas de educar os adultos maduros e as pessoas idosas é lembrar que o potencial humano para o desenvolvimento e para influenciar os outros não se encerra na velhice. No entanto, embora belos e promissores, faz muito pouco tempo que a humanidade acordou para a necessidade de aplicá-los praticamente aos seus maiores. Foi preciso que antes eles incomodassem, não somente a si próprios, como sempre ocorreu com a velhice, mas também a suas famílias, seus locais de trabalho, as economias e os sistemas previdenciários de seus países. Quando eles ganharam maior visibilidade por causa do envelhecimento populacional e por causa do aumento da longevidade, várias sociedades passaram a tomar providências práticas para garantir o que passou a ser reconhecido como direito desse grupo etário e como necessidade social. Foi exatamente nesse contexto que apareceram as primeiras iniciativas de proporcionar educação aos mais velhos.

Embora não sejam o único locus para o cumprimento dessa finalidade, primeiro na Europa e depois na América, as universidades responderam prontamente a esse novo chamado, muito possivelmente porque, a partir do final dos anos 1960, novos conceitos sobre as suas finalidades deitaram raízes nas consciências dos jovens e depois nas dos políticos da educação. Foi nos departamentos e nos espíritos empenhados em transpor o fosso que separava a universidade da sociedade, bem como nos envolvidos no repensar das relações entre as duas instâncias que primeiro medrou a idéia de acolher os mais velhos. Nasciam as Universidades da Terceira Idade, aparentadas, sim, com antigas iniciativas de proporcionar alfabetização, informações sobre saúde, educação religiosa e educação para o trabalho a adultos de alguma forma desfavorecidos pelo sistema educacional, mas singulares no sentido de que amparavam os direitos e contemplavam as possibilidades de educação, bem-estar, produtividade e engajamento social de um segmento até então relegado ao esquecimento que precede a morte (CACHIONI, 2002). 
As primeiras iniciativas brasileiras de oferecer lazer e educação a adultos maduros e idosos aconteceram na década de 1970, quase que simultaneamente ao aparecimento das Universidades do Tempo Livre, dos Grupos de Convivência e das Universidades da Terceira Idade européias e norte-americanas. Embora o contexto aqui fosse outro, no que tange à presença de idosos, à consciência da sociedade e ao avanço das universidades, fomos afetados pelo processo de internacionalização da Gerontologia que já estava em curso. De sua pauta fazia parte chamar a atenção para a velhice como questão médico-social e para a educação como providência que poderia favorecer a solução dos problemas dos idosos. Com essas idéias importamos a denominação terceira idade, que na Europa nasceu como alternativa ao termo velhice, julgado carregado demais de peso negativo, a ponto de precisar ser substituído por outro mais agradável aos ouvidos dos idosos e dos não-idosos.

No Brasil, o ingresso da universidade na área da velhice vem sendo lento, seletivo e gradual. Nas décadas de 1960 e 1970, foram criados os primeiros serviços de geriatria, no Rio de Janeiro, no Rio Grande do Sul e em São Paulo. As primeiras teses e dissertações apareceram em meados dos anos 1970; desde então seu número vem aumentando, principalmente na Região Sudeste e em cursos de pós-graduação em Psicologia, Educação, Ciências Sociais, Saúde Pública, Serviço Social, Enfermagem e Medicina. No período 1975-1999 foram identificadas cerca de 300 dissertações e teses defendidas nas áreas de Psicologia e Ciências Sociais (GOLDSTEIN, 2001). O Instituto Sedes Sapientiae, em São Paulo, foi pioneiro na formação de especialistas para atuar com idosos em nosso país. Desde 1982, oferece cursos de especialização e atualização, destinados a profissionais graduados em quaisquer áreas de conhecimento.

Realizamos no período de 2001-2005 um levantamento para conhecer qual a natureza da participação da universidade brasileira na área gerontológica. Localizamos 47 instituições brasileiras que oferecem cursos de pós-graduação na área gerontológica: quatro universidades oferecem curso de pós-graduação stricto sensu em gerontologia; dois oferecem curso pósgraduação lato sensu em geriatria; cinco universidades contam com programas de pós-graduação stricto sensu que possuem linhas de pesquisa ou áreas de concentração em geriatria; outras oferecem cursos de pós-graduação lato sensu em gerontologia e em áreas conexas (CACHIONI, 2002).

$\mathrm{Na}$ década de 1990, a atenção da universidade à questão social e científica da velhice tornou-se mais nítida, expressando-se, por um lado, no aumento numérico da produção científica no campo e, por outro, no interesse 
em abrir espaço para cursos de pós-graduação lato sensu. Tais eventos são um reflexo dos investimentos ideológicos, educacionais e científicos havidos nas décadas precedentes e encontraram um complemento importante que foi a abertura de um grande número de Universidades Abertas à Terceira Idade em todo o país (CACHIONI; NERI, 2004).

Em 2005, inaugurou-se um novo cenário na gerontologia brasileira com a abertura do primeiro Curso de Gerontologia na Escola de Artes, Ciências e Humanidades da Universidade de São Paulo. Foi concebido de modo a desenvolver, no futuro profissional, habilidades multidisciplinares associadas às necessidades físicas, psicológicas e sócio-culturais dos idosos. Ao final do curso, o aluno será capaz de (PROJETO POLÍTICO PEDAGÓGICO, 2006):

a) atuar em instituições públicas e privadas de saúde (hospitais, ambulatórios, unidades básicas de saúde, centros e hospitais-dia, centros de referência, centros de convivência, programas e serviços de assistência domiciliar) e instituições de ensino e pesquisa;

b) desenvolver processo interativo e complementar com os diversos níveis de complexidade da rede de atenção à saúde;

c) auxiliar o idoso e seus familiares a encontrar os serviços adequados às suas necessidades assistenciais, auxiliar no planejamento, acompanhamento e avaliação dos resultados obtidos;

d) coordenar ações de assistência à saúde do idoso e sua família;

e) atuar em equipe multiprofissional de atenção ao idoso;

f) analisar criticamente a realidade de atenção ao envelhecimento propondo ações criativas para solucionar os problemas encontrados, levando em conta o perfil epidemiológico, os fatores sócio-políticos e culturais, a tecnologia, os equipamentos, os recursos disponíveis e necessários à prática profissional;

g) contribuir para a construção do conhecimento gerontológico por meio do ensino e da pesquisa;

h) contribuir na formação de recursos humanos na área da Gerontologia.

$\mathrm{Na}$ universidade, através dos grupos comunicativos das diversas áreas de conhecimento e atuação profissional e estudantil, podem-se estabelecer conteúdos diferentes de esclarecimento em torno das questões do envelhecimento. A pesquisa, como o local de construção do conhecimento, pode dar base científica ao ensino e, pelos currículos, podem-se construir diferentes discursos acadêmicos. A extensão com a presença dos idosos pode constituir-se como espaço de interpretação das descobertas aponta- 
das pelas pesquisas. Enfim, todo o potencial e as implicações da velhice podem ser objeto de investigação no ambiente institucional e produzir uma reinterpretação cultural.

Em estudo realizado por Both (2000) sobre as mediações do Estado e da universidade sobre a identidade existencial na velhice, o autor afirma que a universidade, pela sua responsabilidade na conquista da cidadania, configura-se num lugar onde a vida humana é reaprendida. Por meio do ensino, da pesquisa e da extensão, pode ser mediadora do perfil do último estágio do ciclo de vida, não só afastando a dor, promovendo a saúde, oferecendo novos objetos de paixão para o pensar e o amar, novas formas de interação social, mas constituindo-se em elaboradora de novos discursos. Nas relações da universidade com as questões da velhice e com a presença dos idosos, são postos como temas desde a inserção social até aspectos sobre a solidariedade entre as gerações.

Both (2000) ainda apresenta os caminhos que a universidade pode assumir para o investimento nas questões da velhice:

a) cursos de pós-graduação com características interdisciplinares são instrumentos interessantes e relevantes, principalmente porque multiplicam a sensibilidade, o interesse e o conhecimento na terceira idade;

b) programas interdisciplinares de pesquisa dão conta da necessidade de um aprendizado holístico sobre o envelhecimento;

c) promoção de programas que visem às relações intergeracionais e suscitem novas representações sobre a longevidade;

d) revisão dos currículos universitários, renovando o entendimento e as abordagens das diversas áreas com a intenção de construir um aprendizado voltado para o desenvolvimento humano em todo o seu ciclo.

Ao analisar a importância e o impacto da presença de idosos nas universidades espanholas, Santiago (2001) salienta que, com as portas da universidade abertas a todos, surge para os idosos um mundo novo carregado de possibilidades que, por sua vez, abrem novas portas para o futuro e revertem em todas as pessoas, seja qual for sua idade, porque:

a) flexibiliza-se a consciência social para as necessidades de cada grupo etário. Os idosos sentem a necessidade de seguir investindo no seu desenvolvimento pessoal através da educação, transmitindonos a mensagem de que o desenvolvimento e o crescimento pessoal são permanentes ao longo de toda a vida; 
b) aumenta-se o crescimento pessoal. A universidade se converte num cenário comum dos idosos, onde podem dividir novas experiências e conhecimentos. Igualmente, oferece a possibilidade de ter uma maior freqüência e riqueza nas relações interpessoais, proporcionando bem-estar físico, psíquico e social; conseqüentemente, uma melhor qualidade de vida;

c) promove-se a convivência intergeracional. A universidade oferece um espaço comum em que fluem os interesses de pessoas de outras idades, promovendo a comunicação e criando o caminho, para a transmissão de informação, idéias e valores entre as diferentes gerações, de forma direta e pessoal;

d) é uma via excepcional de promover a cultura popular. Os idosos acumulam a sabedoria e os costumes que um povo tem. $\mathrm{O}$ espaço universitário, tradicionalmente reservado aos jovens, oferece um espaço de troca entre esta cultura tradicional e as novas tecnologias e conhecimentos trazidos das ciências e das humanidades.

Em Cachioni (2002), verificamos um extenso levantamento do perfil educacional e profissional de 102 docentes oriundos das principais modalidades de Universidades da Terceira Idade brasileiras. Através da análise dos dados, a pesquisa demonstrou que a presença dos idosos nestas instituições despertou o interesse e possibilitou a inserção na área gerontológica de profissionais das diversas áreas do conhecimento; abriu linhas de estudo e pesquisa sobre questões relativas à velhice e ao envelhecimento; criou oportunidade de convivência e novas possibilidades de trabalho entre indivíduos de diversos grupos etários. Além dos ganhos profissionais, os professores se descreveram como altamente motivados pelo trabalho que realizam, e como pessoas que usufruem dos benefícios que a convivência com os idosos e a tarefa de ensiná-los podem proporcionar. Relataram o impacto positivo sobre o próprio bem-estar psicológico, impacto esse potencializado por um contato extremamente amigável, pela troca de experiência de vida e pelo retorno positivo sobre sua atuação por parte dos alunos idosos. Possuem crenças positivas em relação à velhice e reconhecem a grande heterogeneidade desse grupo etário.

Por intermédio da abertura das universidade para os idosos, a educação tem se constituído, mais do que nunca, em um elemento de alto significado para essas pessoas. Certamente já realiza um papel transformador substancial, não só para indivíduos idosos, mas para as sociedades.

Nesse sentido, segundo Alencar (2004), é necessário realçar as múltiplas rupturas promovidas pelo idoso junto às instituições de ensino superior, 
quando se decide participar das atividades disponibilizadas pelas mesmas. Muitas dessas rupturas merecem ser assimiladas e dizem respeito a:

a) maior descentralização do saber produzido nas universidades, o idoso se apropria do conhecimento ali construído através de variadas formas;

b) o saber que o idoso possui, construído por sua experiência de vida, faz o contraponto com o saber acadêmico - antes a única via reconhecida para leitura da realidade no espaço acadêmico;

c) abertura de um novo espaço na universidade e, por decorrência, na sociedade. Com isso, a universidade não é apenas um espaço de conhecimento, mas um espaço de trocas de emoções e de trocas afetivas;

d) inserção de questões centrais da existência humana para discussão no ambiente acadêmico, a exemplo da auto-estima, das perdas, do prazer de viver, da autonomia, da morte;

e) ampliação, na prática, do conceito de educação, que sai da idéia reducionista do círculo produtivo;

f) redimensionamento do conceito de cidadania, tomando-o também como questão de espaço;

g) rompimento dos mitos socialmente incorporados de que o idoso tem dificuldades para aprender, de que é lento, de que tem menor flexibilidade, de que perdeu a capacidade de atenção e concentração;

h) melhor aceitação do próprio envelhecimento ao refletir sobre a vida cotidiana, buscando o aprendizado do ato de viver e de melhor envelhecer;

i) redução da segregação nas relações sociais através da consciência de que envelhecer bem é a meta a ser socialmente buscada; j) manutenção do interesse pelos acontecimentos à sua volta;

k) oportunidade de acesso aos vários tipos de saber construídos pelas diferentes áreas do conhecimento.

A educação na perspectiva do envelhecimento motiva o idoso a assumir a vida tendo consciência da totalidade de si mesmo. Envelhecer aprendendo é ter oportunidade de passar a vida a limpo, cotidianamente, sabendo do muito que ainda tem a aprender.

A velhice, sem dúvida, está mudando a educação; e esta, sem dúvida, está reeducando a sociedade para um novo envelhecer.

Diante desse novo cenário, parece-nos importante conhecer a percepção sobre a presença dos idosos no espaço institucional de coordenadores 
de programas e serviços na área gerontológica. Estes profissionais tem contribuído de maneira significativa para a construção e visibilidade da gerontologia nacional. Através do trabalho realizado para atender a população mais velha, novos conhecimentos são gerados, novas perspectivas de gestão para educandos idosos são implantadas. Crenças e atitudes em relação à velhice e ao processo do envelhecimento são revistas através do encontro entre diferentes gerações.

\section{Objetivos}

Estabelecemos como objetivos:

a) conhecer os trabalhos desenvolvidos na área gerontológica em três instituições de ensino superior brasileiras, através da experiência de coordenadores de programas dessas universidades;

b) conhecer a percepção dos coordenadores sobre modificações ou benefícios que a presença dos idosos causam no ambiente institucional.

\section{A Amostra: caracterização das instituições}

Uma questão essencial ao estabelecimento da generalidade dos dados desta pesquisa era garantir que as universidades brasileiras que desenvolvem a área gerontológica estivessem representadas na amostra. Na impossibilidade de trabalhar com representatividade estatística, optamos por selecionar intencionalmente três instituições, sendo uma privada e duas públicas, oriundas de dois Estados brasileiros. Tais instituições foram selecionadas porque, conforme o seu comprometimento com o tema velhice, oferecem oportunidade de educação permanente a adultos maduros e idosos; possuem serviços especializados de promoção da qualidade de vida do segmento idoso, como também geram ensino e pesquisa na área gerontológica; e possibilitam contato intergeracional planejado e sistemático. Em relação à formação de recursos humanos, a instituição privada, situada no Estado de São Paulo, possui um programa de pós-graduação em gerontologia. Oferece atividades de atualização de conhecimentos, sócio-culturais e de orientação em saúde física e mental para maduros e idosos através do programa Universidade Aberta à Maturidade. A instituição pública localizada no Estado de Santa Catarina é pioneira no oferecimento de educação permanente a adultos maduros e idosos e na formação de recursos humanos na área gerontológica. $\mathrm{O}$ grande interesse pelas questões relativas à velhice e ao envelhecimento que 
a presença dos idosos suscitou na instituição e os trabalhos do Núcleo de Estudos da Terceira Idade incentivaram a criação de vários grupos de estudo e pesquisa. A instituição pública oriunda do Estado de São Paulo investiu de maneira significativa sua atuação no contexto da velhice e do processo de envelhecimento com a abertura do Curso de Gerontologia. Trata-se de curso pioneiro no Brasil. Na educação de adultos maduros e idosos, oferece o programa Universidade Aberta à Terceira Idade.

\section{Caracterização dos Sujeitos}

Para evitar distorções que pusessem em risco a confiabilidade das amostras locais, decidimos trabalhar com a totalidade dos coordenadores envolvidos com os programas para os idosos em cada instituição, no período de nossa coleta de dados.

A amostra foi composta por 15 coordenadores de programas na área gerontológica, sendo que sete atuam na instituição privada do Estado de São Paulo, cinco na universidade pública do Estado de Santa Catarina e três coordenadores são da instituição pública do Estado de São Paulo. Doze dos coordenadores investigados estão envolvidos em atividades nas universidades abertas à terceira idade. Todos ocupam cargo de coordenação e atuam na docência. Os mesmos estão também envolvidos na área gerontológica, através de núcleos de estudo ou pesquisa, curso de graduação e dos programas de pós-graduação. Os indivíduos participaram voluntariamente, a partir de nossa solicitação.

\section{Instrumentos}

As questões referentes ao tema velhice nas instituições de ensino superior fazem parte do questionário que cobriu os itens sobre: instituição a que pertence; unidade ou curso que desenvolve trabalhos ou atividades na área gerontológica; desenvolvimento da área; descrição das atividades desenvolvidas; percepção sobre a presença dos idosos na instituição e possíveis modificações no ambiente. No Quadro 1 estão as perguntas. 
Quadro 1 - Envolvimento da Universidade em Relação ao Tema Velhice Entre Coordenadores de Serviços na Área Gerontológica.

\begin{tabular}{|c|c|}
\hline Variável & Perguntas \\
\hline $\begin{array}{l}\text { Trabalhos desenvolvidos em } \\
\text { gerontologia }\end{array}$ & 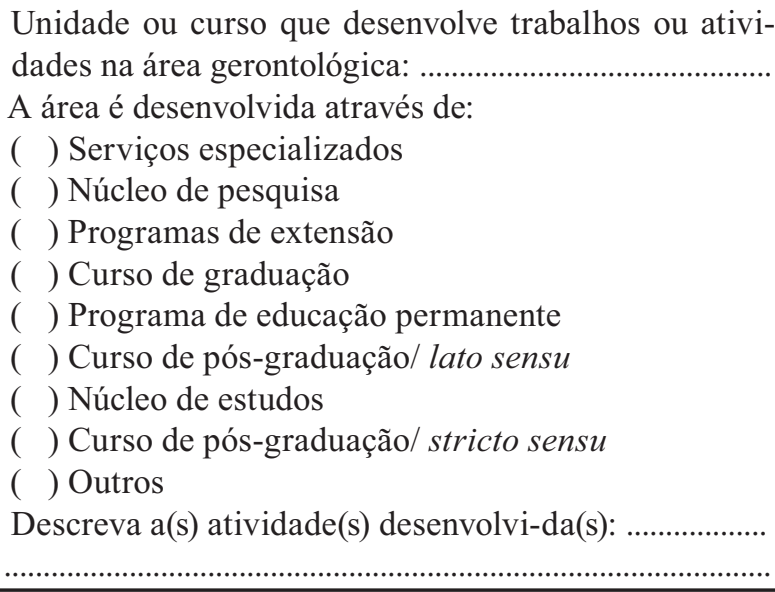 \\
\hline $\begin{array}{l}\text { Modificações ou benefícios } \\
\text { que a presença dos idosos } \\
\text { causam no ambiente insti- } \\
\text { tucional }\end{array}$ & $\begin{array}{l}\text { Você acredita que a presença dos idosos traz modifica- } \\
\text { ções (ou benefícios para o) no ambiente institucional? } \\
\text { Sim ( ) Não ( }) \\
\text { Em caso afirmativo aponte os que ao seu ver são mais } \\
\text { importantes: }\end{array}$ \\
\hline
\end{tabular}

Fonte: Elaborado pela Autora

\section{Análise dos Dados e Resultados}

As respostas dos sujeitos foram submetidas a análise de conteúdo, mediante a qual foram levantadas categorias e subcategorias de respostas (BARDIN, 1977). Nessa tarefa atuaram a autora e uma colaboradora informada, com quem foram discutidas as categorizações e com quem foram confrontadas as análises da pesquisadora principal. Os dados resultantes foram depois submetidos à análise estatística não-paramétrica, assim como os demais dados dos estudos, considerando-se a natureza não aleatória da composição da amostra e o fato de sua distribuição não corresponder à da curva normal de probabilidades (CONOVER, 1971). Nos Quadros 2 e 3 aparecem as categorias que resultaram dessa análise. 
Quadro 2 - Trabalhos Desenvolvidos em Gerontologia.

\begin{tabular}{|c|c|}
\hline Respostas & Categorias \\
\hline $\begin{array}{l}\text { Unidade ou curso na área } \\
\text { gerontológica }\end{array}$ & $\begin{array}{l}\text { - Programa de Educação Permanente / Universidade } \\
\text { Aberta à Terceira Idade } \\
\text { - Programa de Cursos de Pós-Graduação em Geron- } \\
\text { tologia } \\
\text { - Curso de Gerontologia }\end{array}$ \\
\hline Atividades desenvolvidas & $\begin{array}{l}\text { - Coordenação Programa de Educação Permanente / } \\
\text { Universidade Aberta à Terceira Idade } \\
\text { - Aulas terceira idade } \\
\text { - Coordenação pós-graduação gerontologia } \\
\text { - Ensino e pesquisa curso de pós-graduação } \\
\text { - Ensino e pesquisa curso de graduação em geronto- } \\
\text { logia }\end{array}$ \\
\hline
\end{tabular}

Fonte: Elaborado pela Autora

Quadro 3 - Modificações ou Benefícios que a Presença dos Idosos Causam no Ambiente Institucional.

\begin{tabular}{|l|l|}
\hline \multicolumn{1}{|c|}{ Possibilidades / Respostas - Exemplos } & \multicolumn{1}{c|}{ Categorias } \\
\hline $\begin{array}{l}\text { - Encontro de gerações no ambiente escolar. } \\
\text { - Corredor comum (refeitório, biblioteca), uso do mesmo } \\
\text { ambiene facilita o encontro. }\end{array}$ & Contato intergeracional \\
\hline $\begin{array}{l}\text { - Proporciona a criação de uma nova e positiva imagem } \\
\text { do idoso dentro do ambiente da universidade. }\end{array}$ & Mudanças de atitudes positivas \\
\hline $\begin{array}{l}\text { - Novos conhecimentos e aplicação dos mesmos nas práti- } \\
\text { cas educacionais. }\end{array}$ & $\begin{array}{l}\text { Geração conhecimentos geronto- } \\
\text { lógicos }\end{array}$ \\
\hline $\begin{array}{l}\text { - Amplia a perspectiva da universidade. } \\
\text { - É força impulsora para a visualização e novas propostas. } \\
\text { - Marca uma atittude inovadora e cidadã. } \\
\text { - Construção de propostas importantes para o segmento } \\
\text { etário. }\end{array}$ & $\begin{array}{l}\text { Relação da universidade com } \\
\text { a população/ Gestão do novo } \\
\text { segmento etário }\end{array}$ \\
\hline - Aumento do espírito crítico dos alunos. & Benefícios cognitivos idosos \\
\hline $\begin{array}{l}\text { - Aumenta a capacidade do docente em função do conteú- } \\
\text { do cristalizado dos alunos. }\end{array}$ & $\begin{array}{l}\text { Benefícios cognitivos profes- } \\
\text { sores }\end{array}$ \\
\hline - Aumenta a auto-estima do aluno. & Benefícios afetivos idosos \\
\hline - Não há integração entre os idosos frequentadores da \\
$\begin{array}{l}\text { UnATI e os cursos de pós-graduação em gerontologia } \\
\text { criando situações que acirram imagens negativas. }\end{array}$ & $\begin{array}{l}\text { Presença dos idosos suscita } \\
\text { atitudes negativas }\end{array}$ \\
\hline
\end{tabular}

Fonte: Elaborado pela Autora 
A Figura 1 apresenta a distribuição dos coordenadores pelas instituições. Podemos observar que o maior número de sujeitos investigados pertence a Instituição Privada.

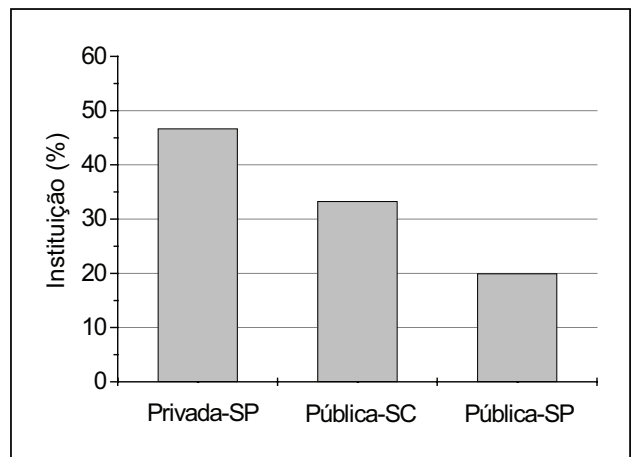

Figura 1 - Distribuição dos Coordenadores pelas Instituições Fonte: Dados obtidos na pesquisa.

As unidades ou cursos na área gerontológica e as atividades desenvolvidas pelos coordenadores nas instituições, estão respectivamente representadas nas Figuras 2 e 3. Apenas três profissionais não estão ligados a programas de educação permanente. Da amostra, 80\% participam de núcleos de estudo ou de pesquisa em gerontologia, e cerca de $60 \%$ estão vinculados a programas de pós-graduação na área gerontológica.

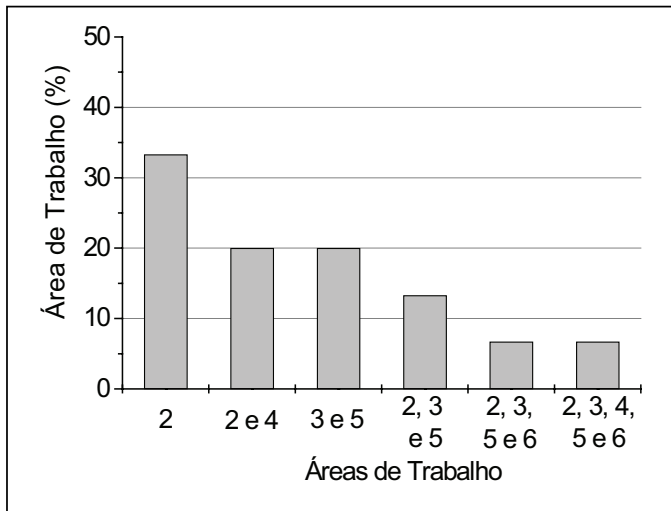

1-Serviços Especializados

2-Programa de Educação Permanente

3-Núcleo de Estudo e Pesquisa

4-Curso de Graduação

5-Curso de Pós-Graduação

6-Outros (Articulação Entidades

Organizadas da Sociedade Civil e

Consultoria a Prefeitura Municipal)

Figura 2 - Unidade ou Curso na Área Gerontológica

Fonte: Dados obtidos na pesquisa. 


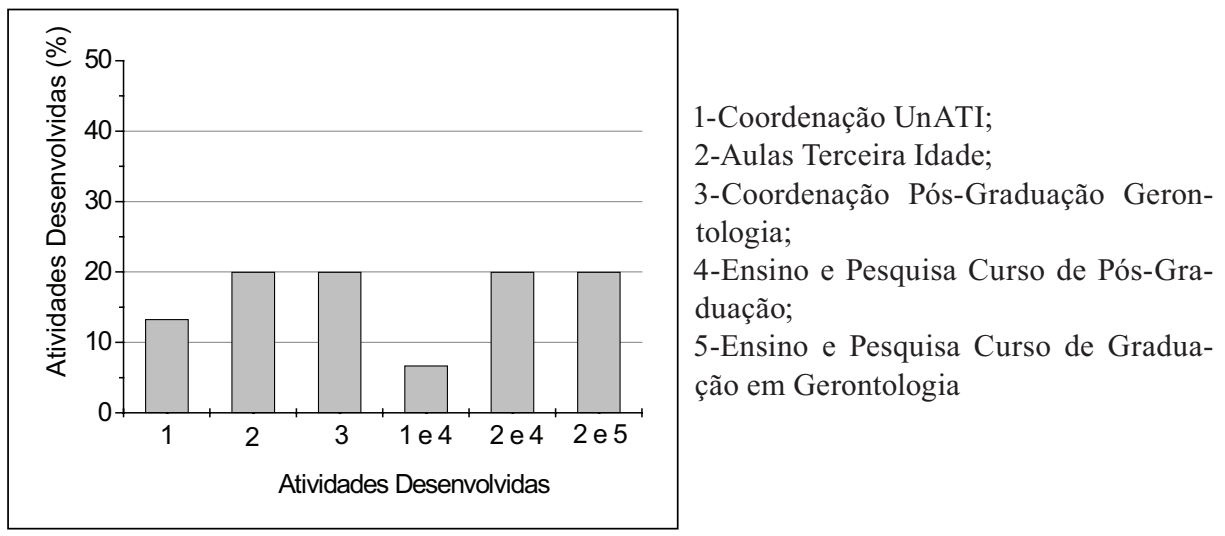

Figura 3 - Atividades Desenvolvidas

Fonte: Dados obtidos na pesquisa.

Contato intergeracional, geração de novos conhecimentos gerontológicos, mudanças de atitudes positivas em relação à velhice, gestão do novo segmento etário/relação da universidade com a população, foram as modificações ou benefícios em virtude da presença dos idosos na universidade mais apontadas pelos coordenadores. A avaliação mais positiva da amostra foi contato intergeracional. Cem por cento dos docentes do Curso de Gerontologia relataram contato intergeracional e geração de novos conhecimentos gerontológicos.

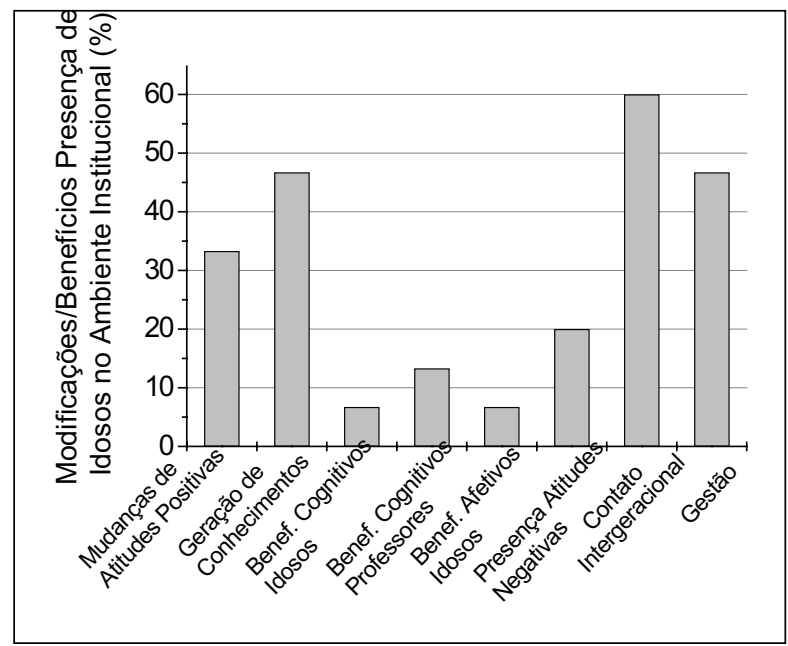

Figura 4 - Percepção sobre Modificações e Benefícios Resultantes da Presença dos Idosos nas Instituições

Fonte: Dados obtidos na pesquisa. 


\section{Discussão}

Considerando-se a análise dos dados, podemos afirmar que a área gerontológica nas instituições investigadas está representada por programas de educação permanente, sendo as universidades abertas à terceira idade a dominante dessa modalidade, por programas de pós-graduação em gerontologia lato e stricto sensu e pelo pioneiro curso de gerontologia da Instituição Pública do Estado de São Paulo.

Na Instituição Privada investigamos coordenadores da Universidade Aberta à Maturidade, bem como coordenadores do Programa de Estudos Pós-Graduados em Gerontologia. A Universidade Aberta à Maturidade é uma proposta de educação permanente que segue o tradicional modelo francês. Trata-se de um dos primeiros programas instalados na década de 1990 no Estado de São Paulo. O curso é divido em três módulos oferecidos em quatro semestres:

a) reciclagem e atualização cultural: prevê estudos nos campos da sociologia, antropologia, política, economia, história, filosofia, psicologia;

b) orientações práticas para uma vida alegre e saudável: como cuidar da sua saúde física e mental com conhecimentos da áreas de geriatria, psicologia, fonoaudiologia e nutrição;

c) atividades socioculturais: contato com o clássico e com o moderno no que diz respeito à literatura, música erudita e popular, artes plásticas, cinema. O Programa de Estudos Pós-Graduados em Gerontologia, Mestrado, possui as seguintes linhas de pesquisa:

- Gerontologia: Teorias e Métodos - investigação dos fundamentos teóricos e metodológicos da Gerontologia como área de saber radicada nos princípios da complexidade e da interdisciplinaridade. Pesquisa das múltiplas dimensões do envelhecimento e da velhice e das interfaces entre os saberes constituídos e os do segmento idoso;

- Gerontologia: Envelhecimento - processos e práticas sociais, políticas e institucionais. Investigação das políticas públicas, das organizações da sociedade civil e de práticas institucionais voltadas ao segmento idoso. Mapeamento, identificação e análise dos diferentes serviços e espaços da existência do idoso na sociedade brasileira.

Na Instituição Pública do Estado de Santa Catarina coletamos dados junto à coordenação do Núcleo de Estudos da Terceira Idade (NETI), pro- 
fessores de cursos de pós-graduação, coordenadora do programa do Centro de Desporto. O Núcleo de Estudos da Terceira Idade, pioneiro nas questões do envelhecimento em nosso país, oferece atualmente os seguintes cursos e atividades: Curso de Formação de Monitores de Ação Gerontológica, Grupos de Crescimento Pessoal I, II e III, Grupo Os Avós na Universidade, Formação de Monitores de Ação Gerontológica, Grupo de Encontro de Amigos, Contadores de Histórias, Oficina de Criatividade, Oficina Teatro Canto da Memória, Italiano, Inglês, Espanhol, Francês, Esperanto. Até o ano de 2006, frequentaram o NETI 4.796 idosos. O Curso de Especialização em Gerontologia considera a interdisciplinaridade como eixo norteador do projeto político-pedagógico, os alunos são estimulados a elaborarem as monografias em grupos multiprofissonais. Este propósito visa a oportunizar uma vivência prática dos princípios gerontológicos baseada em exercício interdisciplinar. No período de outubro de 1992 a agosto de 2005, formou 220 especialistas. O Centro de Desporto oferece Ginástica para a Terceira Idade e Grupo de Dança Folclórica da Terceira Idade. Estes projetos de extensão são realizados há mais de 19 anos. Atualmente, o Centro realiza atividades junto ao município, graças à reconhecida qualidade do trabalho e ao número expressivo de idosos que procuram a universidade.

Os participantes da pesquisa na Instituição Pública do Estado de São Paulo pertencem ao Curso de Gerontologia e a Universidade Aberta à Terceira Idade. O Curso de Gerontologia está fundamentado em três eixos básicos:

a) as bases biológicas do envelhecimento: são desenvolvidos os conhecimentos fundamentais da biologia humana, com ênfase nos processos de envelhecimento, por meio dos seus principais sistemas orgânicos. São ministrados conteúdos de patologia básica, articulados à imunologia, à parasitologia e à microbiologia, em particular aqueles mais freqüentemente associados ao envelhecimento. Ainda neste eixo, são desenvolvidos os conhecimentos e técnicas a respeito do cuidado gerontológico;

b) fundamentos de Psicologia para gerontologia: subsidia a atuação do profissional em Gerontologia com conhecimentos e práticas oriundos da Psicologia. Os alunos são introduzidos inicialmente aos processos psicológicos básicos, em particular àqueles de maior interesse no cuidado do idoso, ou seja, os processos cognitivos envolvendo a percepção, aprendizagem, atenção, memória e motivação. Na seqüência, contatam contextos psicológicos mais complexos, como aqueles que envolvem os aspectos do desenvolvimento, da 
personalidade, das relações humanas e sociais, da saúde e doença mental, para a compreensão e reconhecimento dos aspectos psicológicos envolvidos na atenção ao idoso;

c) envelhecimento, cultura e sociedade: estudos em Sociologia e Antropologia nos aspectos relacionados ao envelhecimento. Ao aluno é dada a oportunidade de refletir criticamente a respeito do envelhecimento enquanto um fenômeno socialmente e culturalmente construído. Com base nesses conhecimentos, os alunos devem analisar criticamente as políticas e programas de saúde, a administração de serviços de atenção destinados aos idosos, as ações e os estudos de caráter epidemiológicos, assim como os aspectos jurídicos e éticos relacionados ao envelhecimento. A Universidade Aberta à Terceira Idade oferece vagas em disciplinas de cursos regulares, como também atividades complementares didáticas apenas para a participação dos idosos. Além das atividades já mencionadas no presente estudo, a partir do início do primeiro semestre de 2007, novas oficinas serão oferecidas: Ateliê de Arte e Criatividade - curso de Tecnologia Têxtil e da Indumentária; Participação Popular e Envelhecimento, Semana do Sono na Terceira Idade, Semana da Saúde e do Envelhecimento, Palestras sobre Demências, Ansiedade e Depressão em Idosos - Curso de Gerontologia. Também no Curso de Gerontologia foram disponibilizadas vagas nas Disciplinas: Processos Psicológicos Básicos para Gerontologia, Ciclo Vital e Ética.

As informações acima resenhadas demonstram parte da história e evolução das questões do envelhecimento nas instituições de ensino superior brasileiras. Nas universidades públicas ou privadas, quer no âmbito do ensino ou da extensão, os idosos estão inseridos. Dados referentes à construção da gerontologia nas universidades em nosso país também são apontados por Goldstein (2001), Cachioni (2002) e Neri (2005). Em Both (2000), o autor afirma que, por meio do ensino, da pesquisa e da extensão, a universidade aprofunda o conhecimento sobre a vida dos mais velhos, bem como possibilita a integração das gerações; permite uma mudança real na vida dos idosos, assim como uma democratização no acesso à educação e à cultura.

Outro aspecto abordado neste estudo foi como os coordenadores de programas, através da presença dos idosos no ambiente institucional, avaliam o tema velhice. Seus auto-relatos apontam principalmente para as seguintes modificações ou benefícios: contato intergeracional, geração de 
conhecimentos gerontológicos, mudanças de atitudes positivas em relação à velhice, relação da universidade com a população/gestão do novo segmento etário.

A avaliação mais positiva nas três instituições foi contato intergeracional, que pode ser verificada por intermédio dos seguintes auto-relatos: vivência intergeracional no mesmo ambiente; vivências práticas no mesmo espaço educacional com idosos, alunos, funcionários e professores; possibilidade de intercâmbios entre gerações; encontro de gerações no ambiente escolar; corredor comum (sala de aula, refeitório, biblioteca), experiência de vida e seriedade no envolvimento das atividades com as demais gerações. Sobre a importância dos contatos intergeracionais, autores como Santiago (2001) e Both (2000) evidenciam que a utilização dos espaços comuns e a oportunidade de desenvolvimento de atividades conjuntas contribuem para a construção da cidadania e o respeito entre gerações. Para Cachioni e Palma (2006), a educação ocupa cada vez mais espaço na vida das pessoas à medida que aumenta o papel que desempenha na dinâmica das sociedades modernas. Esse fenômeno tem várias causas: a divisão tradicional da existência em períodos distintos - o tempo da infância e da juventude consagrado à educação escolar, o tempo da atividade profissional adulta, o tempo da aposentadoria - já não corresponde às realidades da vida contemporânea e, ainda menos, às exigências do futuro. Atualmente, ninguém pode pensar em adquirir, na juventude, uma bagagem inicial de conhecimentos que lhe baste para toda a vida, porque a evolução rápida do mundo exige uma atualização contínua dos saberes. Nesse sentido, a universidade, como uma das principais vias propiciadoras da educação, terá cada vez mais diversas imagens corporais participando ativamente da construção do saber.

A geração de conhecimentos gerontológicos derivaram dos auto-relatos: novos conhecimentos e aplicação dos mesmos nas práticas educacionais; discussões e eventos promovidos pelo programa que coloca a questão do envelhecimento; inserção de um novo segmento etário e oportunidade para realização de pesquisas básicas e aplicadas. Confirmando esses dados, Alencar (2004) discute que, com a abertura das universidades para a população idosa, viabiliza-se a construção de conhecimentos em diversas áreas do saber. Pesquisas são implementadas, uma vez que as universidades abertas à terceira idade são locais propícios para a concretização das mesmas, como já apontamos anteriormente. Discursos tradicionais da geriatria e da gerontologia, que vincula preconceitos sobre o envelhecimento, são revistos a partir de uma atitude crítica da universidade. 
É amplamente reconhecida a relação existente entre conhecimentos, atitudes e estereótipos sobre a velhice, assim como se reconhece que exercem papel orientador sobre as ações dos profissionais que lidam com idosos. Diante dessa relação, os coordenadores-professores apontaram atitudes positivas em relação à velhice como benefícios associados à presença dos idosos nas instituições. Derivamos os auto-relatos: estabelece novas posturas no relacionamento e intercâmbio entre gerações de alunos; cria novas atitudes de funcionários e prestadores de serviço em relação aos idosos; proporciona a criação de uma imagem nova e positiva do idoso dentro do ambiente da universidade; contribui para a diminuição do preconceito em relação ao idoso; ajuda na aceitação da coorte etária; percepção única e diversa da realidade; novas imagens corporais. Santiago (2001) e Alencar (2004) afirmam que as relações estabelecidas na universidade proporcionam novas maneiras de perceber o fenômeno do envelhecimento, principalmente no que se refere à capacidade de aprendizagem dos idosos. Cachioni (2002) em estudo realizado com docentes de universidades abertas à terceira idade, demonstra que crenças e atitudes em relação à velhice foram revistas e tornaram-se mais positivas por intermédio do trabalho realizado com os idosos. Segundo Both (2000), a universidade terá parcialmente cumprida sua função extencionista à medida que, juntamente com os mais velhos, afastar os estereótipos, mitos, crenças que depõem contra a dignidade e o viver com qualidade das pessoas idosas.

"[. . . ] não há integração entre os idosos frequentadores da Universidade Aberta à Maturidade e os cursos de pós-graduação em gerontologia, criando situações que acirram imagens negativas". Esse auto-relato demonstra a importância da coesão entre os programas e serviços gerontológicos existentes na instituição, bem como a visão realista dos que possuem conhecimentos específicos na área. Para os profissionais, o programa de educação permanente deve implementar em seu discurso e prática não apenas os direitos do cidadão idoso, como também seus deveres junto à sociedade e aos espaços que divide na instituição. $\mathrm{O}$ empoderamento dos alunos idosos é compartilhado de maneira bastante crítica e consciente pelas docentes.

Os benefícios cognitivos para idosos (aumento do espírito crítico dos alunos), os benefícios cognitivos para professores (aumento da capacidade do docente em função do conteúdo cristalizado dos alunos) e os benefícios afetivos para idosos (aumento da auto-estima do aluno) estão presentes nos auto-relatados dos professores da Universidade Aberta à Maturidade. Semelhantes dados foram verificados em pesquisa realizada por Cachioni (2002). A autora afirma que a relação professor/aluno é percebida como uma 
intensa troca de conhecimentos, em que existe um encontro intergeracional entre dois grupos de aprendizes, um que possui o saber técnico-científico e o outro com a experiência de toda uma vida. As mudanças decorrentes dessa relação possibilitam a adoção de novos valores, crenças e expectativas, que implicam alteração da auto-imagem e da forma de encarar a vida, a velhice e o próprio envelhecimento. Os vínculos afetivos são fortes, os alunos são gratos pela oportunidade de estarem na universidade, realizando um antigo sonho; os professores sentem-se respeitados e valorizados, tendo a oportunidade de resgatar a relação professor/aluno, que para muitos é desgastada.

A construção comunicativa do conhecimento sobre o envelhecimento e a velhice e as implicações práticas da presença dos idosos nas instituições são apresentadas através dos auto-relatos da relação da universidade com a população/gestão do novo segmento etário: amplia a perspectiva da universidade junto à população; é força impulsora para a visualização e novas propostas; marca uma atitude inovadora e cidadã; projeção da velhice; construção de propostas importantes para o segmento etário. A promoção dos esforços educacionais e a implementação dos diversos serviços oferecidos aos idosos têm aproximado a universidade das reais necessidades da sociedade que envelhece. A experiência da Instituição Pública do Estado de Santa Catarina, através dos trabalhos desenvolvidos pelo Núcleo de Estudos da Terceira Idade, aponta para uma série de frutos da interlocução entre a universidade e as solicitações da comunidade idosa. Dentre elas destacam-se: Associação de Monitores da Ação Gerontológica; Grupo de Apoio a Longevidade; Associação dos Artesãos do NETI; Associação Brasileira Alzheimer - Regional Santa Catarina; e Associação Parkinson - Santa Catarina.

À universidade não cabe a solução dos problemas sociais relativos à terceira idade, mas contribuir na compreensão das representações da velhice e na construção de conhecimentos significativos sobre essa fase do ciclo vital. Os coordenadores investigados possuem experiências renovadas em torno da velhice, o que lhes confere um olhar minucioso da realidade do tema, em suas respectivas instituições.

\section{Considerações Finais}

O perfil demográfico altera-se rapidamente; o seu significado social e psicológico merece constantes estudos e adequações. A longevidade pode ser entendida como um problema ou, se bem mediada, pode constituir-se 
em um potencial de desenvolvimento social e pessoal. O investimento da universidade nessa questão pode resultar em conquista de novas opções de desenvolvimento não só para aqueles que envelhecem, mas para toda a população.

As ações das instituições podem ser ampliadas se forem suficientemente inspiradas pela renovação cultural. Desta maneira, espera-se que possamos chegar à promoção de esforços educacionais para engendrar mudanças culturais compatíveis com o progresso individual e cultural numa sociedade que envelhece e, também, à instrumentalização dos profissionais de gerontologia e, através deles, das pessoas que envelhecem, dos profissionais que lidam com elas e da sociedade de modo geral, para perceberem os vários aspectos da velhice e principalmente o seu potencial para o desenvolvimento.

As diversas leituras realizadas pelos coordenadores acerca da presença dos idosos e do tema velhice em suas instituições de ensino superior revelam que os esforços educacionais estão frutificando e mudando a face das nossas universidades. Ela agora também se configura de cabelos brancos e de olhos e ouvidos mais atentos.

\title{
THE UNIVERSITY ENVELOPMENT RELATED TO THE OLD AGE THEME: the words of coordinators of programs
}

\begin{abstract}
The knowledge related to the perception on old age, created in Higher Education Institutions, is scientifically and educationally important. We carried through a study with 15 coordinators of programs in the gerontological area. The objectives aim at: a) knowing about works developed in the gerontological area; b) knowing about the perception of the coordinators on the old age theme in the institutions. Three institutions were investigated, a private one, and two public ones. The instrument used for the survey was a questionnaire about the involvement of the Universities related to the old age theme. The content analysis, throughout which there were categories and subcategories arose from the answers pointed that coordinators-teachers are involved in the gerontological area, through the University programs opened to the old age people, from study centers, researches or programs of postgraduate. The benefits more attributed to the presence of elderly people in the university were respectively: contact between different generations, related to all of the universities; creation of gerontological knowledge; man-
\end{abstract}


agement of a new age segment / relationship between the university and the population; positive attitude changing related to the old age.

Keywords: Old Age. University. Programs in the Gerontological Area.

\section{REFERÊNCIAS}

ALENCAR, Raimunda da Silva. Educação de Idosos: um aprendizado novo para uma nova educação. Memoralidades, Ilhéus, ano 1, n. 1, p. 61-64, jan./jun. 2004.

BARDIN, Laurence. Análise de Conteúdo. Lisboa: Edições 70, 1977.

BOTH, Agostinho. Identidade Existencial na Velhice: mediações do Estado e da Universidade. Passo Fundo: UPF, 2000.

CACHIONI, Meire. Formação Profissional: motivos e crenças relativas à velhice e ao desenvolvimento pessoal entre professores de Universidades da Terceira Idade. $303 \mathrm{f}$. Tese (Doutorado em Educação) - Faculdade de Educação, Concentração em Gerontologia, Universidade Estadual de Campinas, 2002.

CACHIONI, Meire; NERI, Anita Liberalesso. Educação e Gerontologia: desafios e oportunidades. Revista Brasileira de Ciências do Envelhecimento, Passo Fundo, v. 1, p. 99-116, jan./jun. 2004.

CACHIONI, Meire; PALMA, Lúcia Saccomori. A Educação Permanente: perspectiva para o trabalho com o adulto maduro e o idoso. In FREITAS, Elizabete Viana et al. (Org.). Tratado de Geriatria e Gerontologia. 2. ed. Rio de Janeiro: Guanabara Koogan, 2006. P. $1456-1465$.

CONOVER, Willian Jones. Practical Nonparametric Statistics. New York: John Wiley and Sons, 1971.

GOLDSTEIN, Lucila de Lourdes Lucchino. A Pesquisa Gerontológica no Brasil. Especiaria: revista da Universidade Estadual de Santa Cruz, Ilhéus, ano 4, n. 7, p. 7-11, jan./ jun. 2001.

NERI, Anita Liberalesso. A Formação de Recursos Humanos em Gerontologia: o papel da pós-graduação. Arquivos de Geriatria e Gerontologia, Rio de Janeiro, v. 4, n. 3, p. 69-104, 2005.

PROJETO Político Pedagógico do Curso de Gerontologia da Escola de Artes, Ciências e Humanidades da Universidade de São Paulo. São Paulo: Escola de Artes, Ciências e Humanidades, Universidade de São Paulo, 2006.

SANTIAGO, José Manuel Fernández. Intervenciones Institucionales y Conclusiones. In: ENCUENTRO NACIONAL DE PROGRAMAS UNIVERSITÁRIOS PARA PERSONAS 
MAYORES, 3., 2001, Salamanca. Actas Salamanca. Salamanca: Universidad Pontificia de Salamanca, 2001. P. 23-24.

Recebido em: 07-09-2007

$1^{a}$ revisão: $10-11-2007$

$2^{a}$ revisão: 08-04-2008

Aceite final: 13-05-2008 